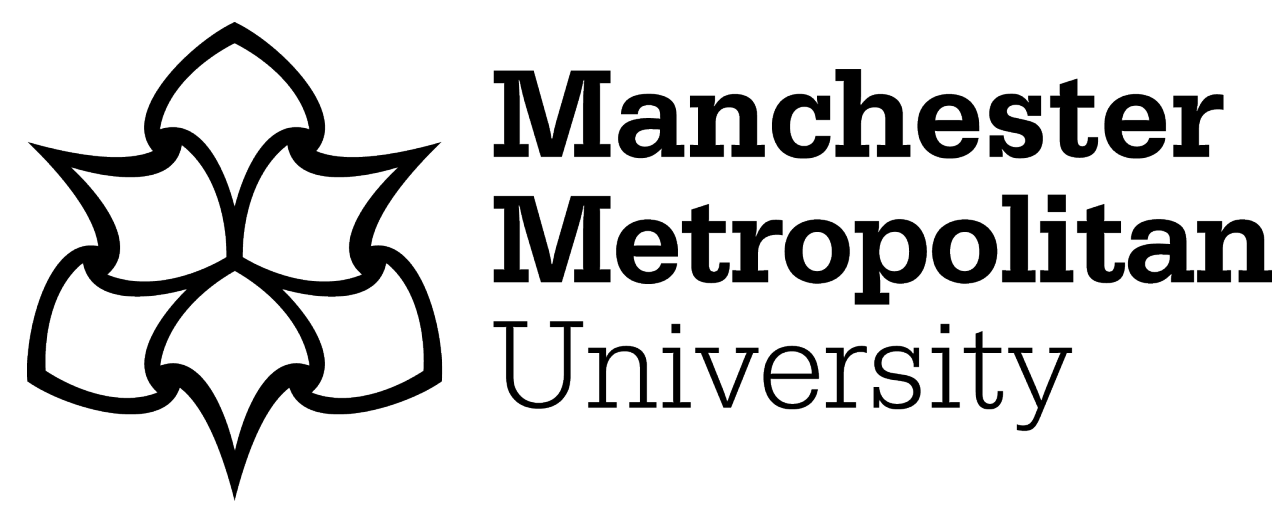

Di Feliciantonio, C and Salvati, L (2015) 'Southern' Alternatives of Urban Diffusion: Investigating Settlement Characteristics and Socio-Economic Patterns in Three Mediterranean Regions. Tijdschrift voor Economische en Sociale Geografie, 106 (4). pp. 453-470. ISSN 0040-747X

Downloaded from: https://e-space.mmu.ac.uk/624365/

Version: Accepted Version

Publisher: Wiley

DOI: https://doi.org/10.1111/tesg.12102

Please cite the published version 


\title{
'Southern' Alternatives of Urban Diffusion: Investigating \\ Settlement Characteristics and Socioeconomic Patterns in Three \\ Mediterranean Regions
}

\begin{abstract}
The present study investigates the relation between urban form and the socioeconomic patterns of the resident population in three southern European cities (Athens, Lisbon and Rome) featured by different processes of urban diffusion. The paper goes beyond the literature on sprawl focused on (residential, income and ethnic) segregation and the different features of the inhabitants of the suburbs and those of the inner cities residents. By integrating multivariate statistics and spatial analysis, a methodology is proposed, based on morphological and socioeconomic indicators available at a fine geographical scale. Results show how urban diffusion processes vary widely according to the context, as does the socioeconomic profile of the actors, stressing the need to think about different 'southern European alternatives' of sprawl.
\end{abstract}

Key words: Sprawl, Mediterranean city, social segregation, economic polarization. 


\section{Introduction: towards a (Southern) European model of urban diffusion?}

The analysis of the increasingly fragmented and dispersed urban forms has represented a main issue for urban scholars in the last decades; sprawl has become a widespread concept, even if it is mainly descriptive and not analytical (Galster et al., 2001, Wilson et al., 2003). If in general terms sprawl can be defined as "the large expansion of cities into surrounding areas by the creation of new low-density suburbs with detached or semi-detached housing and large commercial strips" (Schwarz, 2010: 29), the concept remains ambiguous and disputed (Ewing, 1994, Galster et al, 2001, Johnson, 2001). The acknowledged features of sprawl concern the unevenness and fragmentation of growth patterns, causing an inefficient resources utilization (Bhatta et al, 2010). This ambiguity and vagueness of sprawl as an international feature of urban development result from the tight connection of the characteristics, dynamics and consequences of sprawl with the socioeconomic features of the referred region (Bullard et al, 2000, Duany et al, 2000, Phelps et al, 2006).

Despite having been formulated in relation to the suburbanization pattern of US cities after II World War (e. g. Duany et al, 2000, Ewing, 1997, Harvey and Clark, 1965, Schwartz, 1976), sprawl has become a main research issue also in the European countries (see, among others, Bontje and Burdack, 2005, Cheshire, 1995, Couch et al, 2005, 2007, Patacchini and Zenou, 2009, Schneider and Woodcock, 2008). In order to explain the differences between Northern American and European dimensions of sprawl, these studies stress the need to consider the central role of the path-dependent urban culture, as resulting of these cities' histories. In fact, the US seem to feature an 'anti-urban' attitude, with people according preference to lowdensity residential neighborhoods (Richardson and Chang-Hee, 2004, Vicino et al, 2007), while a 'pro-urban' attitude seems to prevail in Europe (Patacchini and Zenou, 2009). Beyond contrasting urban cultures, these differences can be explained making reference to diverse factors: land availability, socioeconomic indicators, transport systems and infrastructures, the presence of amenities and welfare regimes, among others (Brueckner et al, 1999, Huang et al, 2007, Vance, 1990).

Nevertheless, processes of urban growth and dispersion within Europe are extremely different, making impossible the definition of a single model to describe sprawl around the continent (Gargiulo Morelli and Salvati, 2010). In fact, the strong planning culture of countries such as Sweden and Austria (e.g. reflected in the urban growth trajectories of Stockholm and Vienna) coexists with that featured mainly by informality (e.g. Greece, Portugal, the majority 
of Spanish regions and southern Italy) and the transitional situation of Eastern European cities (Reckien and Karecha, 2007), making the various the urban trends among European regions, as already highlighted in the 1980s by Hall and Hay (1980) and Cheshire and Hay (1989).

In this article we focus on the Southern European model(s) of urban diffusion, comparing selected settlements characteristics with the socioeconomic patterns of the resident population in three cities (Athens, Lisbon and Rome) characterized by a diverging urban form. Athens is primarily defined as a compact, mono-centric region, Lisbon as a fragmented and scattered region, Rome as a poly-nucleated and semi-dense region. In general, there is not a deep consensus in the international literature about the boundaries of the Mediterranean region and several attempts to define the 'Mediterranean city' have found very few common features and a big variety of place-specificities (Catalán et al, 2008, Corna Pellegrini, 1998, Leontidou, 1990, 1996). This 'weak' theory of Mediterranean cities relies on the traditional exclusion of the Mediterranean region from the spaces of European modernity; in fact, "the Mediterranean is treated more as a 'regional' subject rather than a key locus in the production of alternative modernities" (Giaccaria and Minca, 2011: 346). According to Giaccaria and Minca (ibid: 347), what Herzfeld defined as 'Mediterraneanism' $(1984,1985)$ is today still prominent, an essential understanding of the Mediterranean as both an unified, allencompassing and a culturally and naturally fractured space.

The singularity of this region puts into question the valid use of linear approaches; in fact, as stated by Kourliouros (2003) in his discussion about the 'cultural turn' in economic geography from a southern European perspective, this region needs to be investigated based on 'a deliberately holistic political-economic framework including and resynthesizing various aspects and processes of change' (2003: 792). On the same line, Minca (2004) calls for an integration of 'quantitative' and 'qualitative' approaches (e. g. focusing on human/spatial relations) in the research on the Mediterranean, in order to avoid a monolithic view of 'incomplete modernisation ' and marginalization, compared to a rich, fully modern Northern Europe.

About the urban dispersion processes of southern European cities, many studies showed how they diverge deeply from those of both northern Europe and the US (see, among others, Dematteis, 1998, Couch et al, 2007); to give the example of Italy, Calafati talks about an 'Italian style of urban sprawl' reflected in the high settlement dispersion observed in northern Italy (2008). In general terms, it can be argued that informality represented the main feature of 
housing until the 1980s in these countries (Allen, 2000, Barata Salgueiro, 2001, Busquets, 2006, Costa et al, 1991, Leontidou, 1990, 2010), not just tolerated but almost promoted by the State. In fact, inside an institutionalist framework, 'informality must be understood not as the object of the state regulation but rather as produced by the state itself' (Roy, 2005: 149). Informality made the urban tissue of southern European cities chaotic and heterogeneous, with a mixture of residential/commercial functions and the prevalence of vertical differentiation (Delladetsima, 2006).

It is usually acknowledged that the transition of southern European cities from compact towards sprawled forms became prominent in the 1990s, together with the processes of economic and population deconcentration (Gemmiti et al, 2012, Longhi and Musolesi, 2007, Schneider and Woodcock, 2008). Commenting on this process, Dematteis (1998) talks about 'Mediterranean peri-urbanization' and 'territorial metropolization' to describe the moment in which urban development does not occur by contiguity but dilutes in a wider space without solutions of continuity; well-documented cases of this phenomenon are represented by Rome (Munafò et al, 2010) and Athens (Chorianopoulos et al, 2010).

The paper explores the relations between urban morphology and selected socioeconomic patterns of the living population in the three aforementioned metropolitan regions through a methodology integrating multivariate statistics and spatial analysis, based on several morphological indicators taken from national censuses at the enumeration district scale. By highlighting the differences of the socioeconomic patterns associated to the processes of urban diffusion in the referred areas, the paper aims at challenging the monolithic representation of the Mediterranean (and its metropolitan areas). This way, it contributes to enrich the international debate on sprawl, showing how its socioeconomic 'determinants' can be variegated and contradictory.

After a brief presentation of the investigated cities linked to a more general reflection on the return of comparative urbanism in part 2, the developed methodology is explained and discussed in part 3. The results are presented and discussed case by case in part 4, highlighting the new aspects emerging compared to existing literature; finally, in the last part, we summarize our findings, underlining the need to think about diverse southern European urban diffusion processes.

\section{Case studies}


In recent years there has been a resurgence of comparative urbanism as a main discussion issue in urban studies literature (e. g. Bourne, 2008, Kantor and Savitch, 2005, Kloosterman and Lambregts, 2007, McFarlane, 2010, Nijman, 2007, Robinson, 2006, 2011, Ward, 2010), associated with a calling for 'a comparative approach that acknowledges the territorial and relational geographies of cities' (Ward, 2010: 483), 'an approach that seeks to move beyond the rather fixed and static theorizations of place, space and scale that tend to continue to characterize much of the comparative urban studies literature' (ibid: 473).

In order to analyse the relationship between urban form (expressed by six settlement typologies ranging from hyper-compact to dispersed and low-density, see fig.1) and socioeconomic patterns of the resident population in the considered metropolitan regions, several socioeconomic indicators describing the demographic, social and economic features of the population living in the six examined settlement types have been considered. For each case, the area we consider corresponds to the province (or prefecture) administered by that city (extending for 2,982 $\mathrm{km}^{2}$ area in Athens, 2,996 km² one in Lisbon and 5,355 km² in Rome). The analysed areas encompass the boundaries of the related 'Urban Atlas' regions, identified as areas featured by a significant share of the residents' commuting into the main centre. In order to make data comparable among regions, we considered the enumeration districts as in the 2001 population censuses (4,066 units in Athens, 32,057 in Lisbon and 19,635 in Rome). We use enumeration districts in order to have a detailed analysis of buildings' features, human settlements and resident population's socioeconomic patterns at a scale largely used to analyse urban landscape (Lauf et al, 2012, Martinuzzi et al, 2007).

Because of the cities we analyzed belonging to the same geographical area, it seems to contrast with recent critical reflections in urban studies encouraging "all kinds of novel and unusual comparative research to compensate for years of neglect and to challenge entrenched assumptions of incommensurability" (Robinson, 2011: 19). On the contrary, we think that our analysis, focused on three 'strong character' cases, diversely and strongly attached to their history and presenting different social relations shaping them, reinforces a relational comparative approach (Ward, 2010). In fact, these urban regions present diverging form, degree of compactness, population density, demographic trends, economic performances and land-use distribution along the urban-rural gradient. In the next sub-sections, we present the main features of the investigated cities, as emerging in the international literature.

Athens 
Athens has been represented as a prototype of the always-in-transition hyper-compact 'Mediterranean city' (Leontidou, 1990) that, after the diffusion and infrastructural renewal linked to the Olympic games (Chorianopoulos et al, 2010), is still sprawling outside the boundaries of the compact city, generating social tensions and exclusion (Leontidou, 2010, Leontidou et al, 2007). Informality and spontaneity appear as the main features of Athens urban development (Dalakoglou, 2012: 535). Some features of the city urban development highlighted by international literature and being relevant for our study include (i) the historical growth of the city as un-designed, confused, based on self-financed real estate development and lacking expenditure on urban infrastructures (Chorianopoulos, 2003) and (ii) the importance of vertical social differentiation (Maloutas and Karadimitriou, 2001), seen as complementary to community segregation. Moreover, Maloutas (2007) has shown how, during the 1990s, there were both a decreasing segregation of immigrants and increasing social polarization and inequalities. Finally, analysing Athens' socio-spatial segregation in relation to the feminization of migrations and employment, Arapoglou and Sayas (2009) have shown how low-skilled migrant and domestic workers in the service sector locate mainly in the core and suburban areas, domestic 'white collars' and professionals prefer moving to 'upper-class suburbs', small entrepreneurs and self-employed workers sprawl to peri-urban areas, clerks and salespersons tend to move to inner suburbs.

\section{Lisbon}

The analysis of the urban form of Lisbon reveals the presence of sprawl featured by discontinuous urban patches similar to 'oil growing spots' or ribbon low-density urbanization linked to the prominence of informal settlements until the end of the 1980s (Barata Salgueiro, 2001). The growth of Portuguese economy in the 1990s with Lisbon being the main urban recipient for foreign direct investments led to a rapid expansion of the construction sector. In relation to the resident population, during the 1990s Lisbon has become the destination of strong immigration flows; in fact, between 1991 and 2001 the percentage of immigrants in the Lisbon Metropolitan Area (LMA) almost tripled (Fonseca et al, 2002). According to Malheiros and Vala (2004: 1070), the high concentration of immigrants in the LMA is linked to the restructuring of the urban economy towards the service sector, requiring skilled professionals but also many unskilled workers (Malheiros and Vala, 2004). The presence of long-term established immigrants' communities favours the residential concentrations of 
immigrants; in fact, immigrants' networks facilitate both access to housing and entry in the labour market.

\section{Rome}

The fragmented and dispersed urban form of Rome has been described as 'an archipelago of urban islands' (Fratini, 2001). In fact, as time going on, the originally semi-compact city has become more and more fragmented (Munafò et al, 2010). Urban growth followed radial axes starting from the core city and in line with the most important transport routes, generating land fragmentation. In a recent analysis of the changes in the resident population of Rome Metropolitan Area (RMA) in the last decades, Crisci (2010) has shown how, since the 1970s, peri-urbanization has occurred, with the core city losing amounts of resident population in favour of the suburbs. The main actors of this process are young adults who cannot afford to live in the core city, given the high prices of the real estate and the lack of a welfare regime centred on housing (Arbaci, 2008). This process has dramatically modified the ageing structure of the resident population in the core city, as the rate of old people increased more and more in the last forty years. Most of the resident immigrants are women employed as care workers and that they are polarised in relation to housing (Crisci, 2010). The residential segregation of immigrant households has been highlighted by Mudu (2006) who verifies also how the residential choices of young adults' households tend to coincide both for domestic and immigrants.

\section{Methodology}

In order to analyze the relation between low-density urban settlements and the socioeconomic patterns of the resident population, a three-steps multivariate strategy based on the use of indicators taken from official statistical sources has been developed, leading to a classification of urban settlements into homogeneous groups from the morphological perspective.

The first step consisted in a Principal Components Analysis carried out on the original data matrix composed of the indicators selected for each city (Table 1) to extract latent patterns and simplify data complexity. In order to verify the quality of PCA outputs, the Keiser-MeyerOlkin (KMO) measure of sampling adequacy and the Bartlett's test of sphericity were adopted, 
the first aimed at testing if the partial correlations among variables are small together while the second if the correlation matrix is an identity matrix. According to the results of the PCA, an intermediate matrix was developed with $m$ columns representing the PCA factor scores estimated for each enumeration district (Salvati and Zitti, 2009). The PCA identified six relevant latent factors for each case, indicating the most important dimensions of recent urban development and summarizing the key components of urban form in the three investigated regions: settlement concentration and density, vertical profile of buildings, the material and year of construction. Compact settlements are mainly associated to high population density, building's age ranging from 1960 to 1980, and high vertical profile of settlements. To the contrary, dispersed settlements are characterized by low vertical profile and recent construction period, mainly after 1990 (these findings are summarized in table 1). Secondly, a $k$-means Cluster Analysis was applied to the intermediate matrix (the indicators selected for each city $\bullet m$ factor scores) in order to achieve a classification of the enumeration districts into homogeneous urban areas. Following the parsimony criterion, the procedure was conducted for a set of possible solutions (i.e. cluster numbers) ranging from 3 to 10 clusters. The most efficient partition (i.e., the number of clusters chosen in order to gain the most effective discrimination among municipalities) was identified using standard diagnostics that included the pseudo F-statistic and the Cubic Clustering Criterion (Duran and Odell 1974); based on cluster membership, average values of the considered indicators were then calculated for each cluster of districts and for each city. According to the values of the pseudo F statistics and Cubic Clustering Criterion, for each region six clusters form the partition best discriminating morphologically the urban settlements. Figure 1 maps the classification of each enumeration district according to the considered indicators and the statistical analysis for each case. The spatial distribution of the six clusters reflects the distance from the main urban center suggesting that the form of the three cities was at the origins mainly mono-centric. Clusters 4, 5, and 6 (respectively indicating medium-density settlements, low-density settlements and dispersed settlements) are gradually located outside the core cities.

Last step consisted in a linear Discriminant Function Analysis (DFA) aimed at determining which indicators contributed the most to the definition of settlement clusters. Models were estimated by using a linear stepwise DFA model weighted by district surface area. For each city, we considered only indicators entering the discriminant function with a probability level fixed to 0.01 . This way, we profiled spatial units in order to identify low-density, dispersed settlements. Results indicate how the most significant indicators discriminating among the six 
clusters ( $p<0.0001$ in all comparisons) are substantially similar in Lisbon, Rome, and Athens: building's density (high vs low), age of construction (recent years vs the decades immediately following World War II) and vertical profile. This makes data summarized in table 1 comparable among the three cases. However, other indicators have importance at the city level (e.g. UNO and LAR in Rome, CON and ROO in Athens), highlighting the capacity of the methodology to identify both processes observed in all the examined regions and site-specific factors.

\section{Profiling settlement typologies in the three study areas}

In order to analyse the relationship between urban form (compact/dispersed) and the socioeconomic patterns of the resident population, we elaborated the census data regarding building features, population structure and employment in the investigated urban regions at the scale of enumeration district (with a spatial resolution of 1:25,000 in all cities examined). In relation to the settlements' features, we used indicators concerning the building and population density, the building's year of construction, the settlement's vertical profile, the building's construction material, the building's main use (residential or not) and other settlement features (Table 1). By this way, our analysis of urban diffusion fits with the multidimensional definitions of sprawl, as the one by Galster et al (2001). As explained in the previous section, in order to have a consistent analysis for the three cities, six settlement clusters were identified and characterized using the multivariate strategy.

In the case of Athens, the analysis identified a building density gradient from the historical centre to the suburban dispersed settlements, reflecting the rate of adjacent buildings. The hyper-compact and semi-compact settlements together represent more than $70 \%$ of the area (26 and 46\% respectively), while low-density and dispersed ones occupy respectively 1 and $7 \%$ of the whole area. Concerning the Lisbon region, the analysis identified a buildings density gradient from the historical centre to the suburban dispersed settlements, reflecting the vertical profile of the city and the age of buildings. The dispersed and low-density settlements occupy together $36 \%$ of the regional area (28 and $8 \%$ respectively), while the hyper and semi compact ones together register the lowest rate among the three investigated regions (36\%). For Rome's region, the analysis revealed a buildings' density gradient associated to the vertical profile of buildings and to the age of construction. In fact, the vertical profile of buildings is higher in the historical centre and in the hyper-compact settlements. Despite a 
high rate of land occupied by hyper- and semi-compact settlements (54\%), the low-density and dispersed ones together register the highest rate among the three case studies (37\%).

\section{Socioeconomic indicators}

Data used in this article are taken from digital databases developed by the National Institutes of Statistics of Greece (ESYE), Italy (ISTAT) and Portugal (INE) to support censuses. Among the information available from the database, there is a vector map covering the whole investigated areas with the geometry of thousands enumeration districts corresponding to three-five building blocks in urban areas. The surface area of each enumeration district polygon was calculated by way of the relevant ArcGIS 'Spatial analyst' tool (ESRI Inc., Redwoods, USA). For the present study, more than 40 indicators were selected to describe socioeconomic patterns of the resident population (population structure by gender, age, marital status, education, employment and citizenship). The primary data source employed was the General Census of Population and Buildings carried out by ESYE, ISTAT and INE; the indicators were calculated from data collected in a fully comparable way at the enumeration district level in 2001. As stated by Malcata Rebelo (2010: 590), using census data is advantageous because of its reliable information and exhaustive coverage. Not all the selected variables were available for each case study and, when necessary, proxy variables were calculated. However, based on the available indicators, we consider the description of the socioeconomic context as enough articulated to satisfactory identify territorial patterns to be contrasted with the morphological characteristics observed at the local scale in the three cities.

\section{Results and discussion}

In this section, a synthesis of the results of our study is presented. We discuss separately for each case the relation between settlement typology and the observed socioeconomic patterns of the resident population.

\section{Athens}


Results for the Athens' region (summarized in table 2) confirm the existing literature describing the city as a compact city where urban diffusion has been occurring since the 1990s. The historical centre is the area featuring the highest rate of old low-educated people among the residents: almost half of the residents are older than fifty (47\%) and 38\% of them completed only the primary school. These features are reflected in the working profile, registering the lowest employment rate (36\%). Concerning the presence of immigrants among the residents, the historical centre appears as the favourite for those coming from high-income countries (both European and non European): the rate is 7\%, with the general average being $2 \%$. The historical centre presents also high rates of immigrants from lowincome countries $(12 \%)$.

The hyper-compact area seems to be featured mostly by domestic low-middle class; in fact, there is a high rate of waged workers (77\%), especially non-technical employees (14\%) in the retail sector (15\%, the highest rate) and the domestic residents rate is slightly higher than the average. Concerning the educational status, $9 \%$ and $27 \%$ of the residents have, respectively, a university degree or a lyceum diploma (both a bit under the general averages of $11 \%$ and $27 \%)$. The semi-compact area presents the highest rate of people aged under fourteen (21\% of the residents, while the general average is 14\%), determining the lowest mean age (34). Concerning the working status, the rate of waged workers is high (77\%), both non-specialized and qualified workers (14\% and 20\% respectively). The semi-compact area does not seem very attractive for immigrants, in fact it features the highest rate of domestic residents (93\%). The medium density area is the one featuring the highest rates of entrepreneurs and employers (14\% and 16\% respectively), while that of unspecialised workers is the lowest (7\%). The high socioeconomic status of the residents emerges also by looking at the educational status: $13 \%$ of them have a university degree, while the rates of people being illiterate or without educational title are low (2\% and 3\% respectively). The low density area appears as the favourite for most skilled and educated people; in fact, it presents the highest rates of people with a master degree, a university degree or a secondary school diploma (1\%, $15 \%$ and 32\% respectively) and of knowledge workers and non-technical employees (18\% and 14\%). Most of the workers are waged (79\%, the highest observed rate), while the rate of self-employed workers is the lowest (10\%).

The dispersed settlements area presents a high rate of old people among its residents, in fact people aged over fifty are the $39 \%$ of the total population. Considering the educational status, it features the lowest rates on population with high-educational status; consequently, if we 
look at the working status, data show high rates of qualified and unspecialized workers (20 and $13 \%$ respectively), while the rate of knowledge workers is low (7\%), in a context of high unemployment (17\%). The immigrant residents of the area come mainly from low-income countries (10.2\% of the overall residents).

Data on the Athens area depict an originally hyper-compact city where urban diffusion has occurred since the 1990s, whose main actors are medium-upper class and white collars families (e.g. knowledge workers, entrepreneurs), especially for the low-density area. At the same time, sprawled areas appear to attract also immigrants from low-income countries and, more generally, people featuring a low socioeconomic profile (as confirmed by the unemployment rate of the dispersed area). On the contrary, the historical centre seems to feature a dual social structure: on one side there are many old people and lowincome/education families (unspecialized and care workers, immigrants from low-income countries), on the other many white collars (both domestic and immigrant from high-income countries) locate there. Finally, the hyper and semi-compact areas are the most privileged for low-middle class families with children, mainly waged workers with a relatively high education.

\section{Lisbon}

In the Lisbon case (table 3), our analysis shows that the biggest amounts of population are found in the historical centre and in the low-density area. The historical centre features a high rate of old people: in fact people aged over sixty-five represent the $20 \%$ of the residents, determining a high value for the ageing index (248), compared to the grand average (187). The work profile of the residents is featured by a high rate of workers in the service sector (34\%) and retired people (23\%), pushing the employment rate under the overall average (45.8\% vs $46.6 \%)$.

The hyper-compact area appears as very attractive for middle-upper class households made of more than two people with children. In fact, the area features an elevated rate of three or four members households (53\%, while the average is $44 \%$ ) and the highest ones concerning households composed by at least one member aged under fifteen (46\%). At the same time, it presents the lowest rate of households with at least one member aged over sixty-five (10\% while the general average is $31 \%$ ), leading to a low value for the ageing index (37). As far as the educational profile of the residents is concerned, it features the highest rates of people 
having a university degree or a high school diploma (16\% and 19\% respectively). These demographic and educational features are reflected in the working profile of the resident population, registering the highest rates of employment (56.5\%) and a very low rate of retired people (6.6\%).

The semi-compact area seems to locate mainly low-income households showing low homeownership rate (51\%); on the same time, $40 \%$ of the households are tenants, while the general home rental rate is $24 \%$. Regarding the resident households structure, most of them are mono-nuclear or bi-nuclear (59\% with the grand average being 48\%), with a high prevalence of old people. In fact $44 \%$ of them have at least one member aged over sixty-five (the rate for the overall city is $31 \%$ ). The low social status of the area is proven also by the educational indicators, whose values are all under the grand average for the higher educational titles, while the rate of people without any educational title is high (17\%).

The medium-density area seems to 'average' the socioeconomic patterns of the overall metropolitan region, all the indicators being close to the grand average. The low density area residents show a socioeconomic profile very similar to the ones living in the hyper-compact one. In fact, there are high rates of large households (54\% of them are composed by three or four members and $9.6 \%$ by at least five members, both being the highest rates) with children (in $40 \%$ of them at least one member is aged under fifteen). All the indicators for higher education titles are above the general average and, at the same time, the employment rate is high (51\%). The middle-upper class status of the residents is proved also by the homeownership rate (90\%), while just $7 \%$ of the households are tenants. The socioeconomic patterns of the residents in the dispersed area resemble the low status of those living in the semi-compact area. This is proven by the rates regarding the educational and working profile of the residents. In fact, people having a university degree represent just 6\% (the lowest rate) and the employment rate is lower than the average (45\%).

The results presented in this section show how, in the Lisbon case, the relation between urban diffusion and the socioeconomic patterns of the resident population is complex and differentiated. In fact, middle-upper class households (highly educated and employed especially in the service sector, many students) tend to be located mainly in two diverging territorial contexts (i.e. the hyper-compact and the low density areas). Similarly, low class households are located mostly in two diverging contexts (namely semi-compact and dispersed settlements). This confirms the existing literature describing the importance of informal settlements in less compact areas from the 1960s. 
Rome

For Rome's region, results (summarized in table 4) depict the complex relation between the urban geography and the socioeconomic features of the city, unveiling some important aspects not yet highlighted by existing literature. The historical centre emerges to be mainly the residential location of small households of middle and upper class old people; this is easily visible by considering the aging and the population replacement indexes and the mean age (255, 214 and 45 respectively). The socioeconomic status of the residents is showed by their educational level $(22 \%$ of the residents have a university degree and $54 \%$ at least a high school diploma) and working profile (the employment rate is $40 \%$, retired people are the $18 \%$ and the area has the highest rates of entrepreneurs and people employed in real estate and education sectors - respectively $15 \%$ and $11 \%$ ). The high value of the real estate properties and the small dimensions of households are reflected in the housing features of the area: it has the highest rate of home rental (30\%), the mean size of houses is the second lowest ( $88.6 \mathrm{~m}^{2}$ for houses inhabited by residents, $85 \mathrm{~m}^{2}$ for those not inhabited by residents). At the same time, the rate of six rooms houses is high (15\%), this showing the high social status of the properties. The socially prestigious status of the areas influences also the residential choices of immigrants; in fact, in the historical centre, $40.6 \%$ of the resident immigrants come from EU countries.

The hyper-compact area appears as the favourite for middle class households lead by people aged over fifty and employed in the public administration. In fact, the values of both the aging and the population replacement indexes are high (209 and 199 respectively) and the rate of waged workers is the highest (77\%), with the most important employing sectors being public administration, real estate, education and health (15\%, 11\%, 8.7\% and 8.5\% respectively). Concerning the educational profile of the residents, the area registers high rates of both people having a university degree (15.5\%) and at least a high school diploma (49\%).

The semi-compact area seems to privilege the residential location of low-middle class households with children. In fact, even if bi-nuclear households present the highest rate (26.7\%), three and four members households register important rates $(22 \%$ and $21 \%$ respectively), with the aging population index being lower than the average (139 vs 164). About the occupational profile of the residents, the employment rate is lower than the overall 
average, with the most important employing sectors being manufacturing, transports, buildings and, above all, commerce/restaurants/hotels.

Compared to the others, the medium density area appears to locate mostly low income and housing profile households, lead by old people. In fact, it presents a high rate of small size houses (18\%) and the value of the aging index is 210 . The working profile of the residents shows ambivalent results, in fact the employment rate is higher than the average (43\% vs 39\%), but important sectors are the primary, the commerce/restaurants/hotels and the public administration ones, while the rates of entrepreneurs and self-employed workers are low. About the resident immigrants, $76 \%$ of them are originally from non-EU countries.

The socioeconomic profile of the residents in the low density area is similar to that of the residents in the semi-compact one. In fact, it features the highest values in households size (2.7 members), while the rate of mononuclear households is the lowest (20\%). The low(er) educational profile of the residents (8\% of them having a university degree and 38\% having at least a high school diploma) influences also their working profile, the unemployment one being the highest (9\%) and a high employment rate in the building sector (9\%).

So data presented in this section show how complex and fragmentary the urban diffusion process has been in Rome's metropolitan area (Fratini, 2001). In fact, if the historical centre appears as the favourite residential location of middle class households constituted mainly by one or two old people and a similar trend can be observed in the hyper-compact area, less coherent patterns can be found in the other cases. What emerges clearly is that younger households with children prefer more dispersed and peripheral locations, confirming what already shown by existing literature. This can be surely explained by making reference to the high values of the real estate market in the historical centre and the availability of larger and cheaper houses in the suburbs.

\section{Conclusions: diverse Southern European alternatives of urban diffusion?}

In the present paper, an investigation of the relationship between urban form (by considering selected morphological features of settlements) and the socioeconomic patterns of the resident population has been presented, focusing on three southern European cities (Athens, Lisbon and Rome) that have been usually described in existing literature as prototypes of different urban forms (respectively compact and dense, dispersed-fragmented and semicompact and poly-nucleated). Based on simple indicators taken from national censuses, a three-steps multivariate strategy was developed in order to define homogeneous areas in 
terms of urban morphology. For the three investigated urban regions, the analysis allowed identifying six settlements' clusters (old centre, hyper-compact, semi-compact, mediumdensity, low-density and dispersed settlements). In the present study selected socioeconomic indicators of the resident population were compared between the six clusters to define the (possibly different) social and economic profile of population in 'compact' and 'sprawling' settlements in southern European cities with different urban form. This approach revealed innovative to the international audience since the socioeconomic profile of sprawled areas has been usually analysed in terms of (class and ethnic) segregation or by focusing on the demographic features of the residents in the suburbs in opposition to those of the inhabitants of the core cities, but no study has compared the socioeconomic patterns of residents based on settlements' density clusters and urban form.

For the three cases, results show different relations between urban form and the socioeconomic profile of the resident population. In fact, in the case of Athens, the main actors of urban diffusion appear to be medium-upper class, white-collar households (firstly knowledge workers and entrepreneurs), that moved out of the city centre mainly in the 1990s profiting of the urban diffusion processes linked to the city Olympic regeneration. Lowdensity and dispersed areas, however, seem to attract also immigrants from low-income countries and, more generally, less advantaged groups. This duality emerges as featuring also the old city centre, whose inhabitants are mostly low-income/education households of old people on the one side and white collars (both domestic and from high-income countries) on the other side.

Regarding the Lisbon area, our analysis partly confirms the existing literature on the informal settlements' development observed since the 1960s, that led to a semi-polycentric urban structure affecting in a complex manner the socioeconomic profile of the residents. In fact, low-income households, constituted mainly by old retired males poorly educated and living in depriving housing conditions, tend to be over-represented in the semi-compact and dispersed areas, while middle-upper class households including highly educated people employed in the service sector, seem to prefer the hyper-compact and the low-density areas.

This complex and fragmented relation can be observed also in Rome's region, for which our analysis confirms the definition of an 'archipelago of urban islands' proposed by Fratini (2001), constituted by a compact centre and a large amount of recently built-up dispersed neighborhoods. Considering the socioeconomic profile of the residents, the prestige of the historical centre determines high real estate values, making it as the residential location of 
mono-nuclear and bi-nuclear middle and upper class households, constituted mostly by old people. If a similar pattern emerges for the hyper-compact area, no linear relation can be found for the other ones, the only well defined trend being that young(er) households with children prefer more dispersed and peripheral locations.

Results depict how the forms of urban diffusion processes can be diverse even in the case of originally-compact cities located in an area usually described as homogeneous, such as the Mediterranean Europe (Herzfeld, 1984, 1985), challenging, by this way, the monolithic vision of the social consequences of sprawl as generating segregated and class-uniform suburbs for middle and upper class households. In contrast with most of the existing literature, the present study shows how 'southern European alternatives' (reminding Giaccaria and Minca's formulation, 2011) can be found in the ambiguous process usually referred as 'sprawl'. As already highlighted by many scholars (e. g. Robinson, 2006), our analysis calls into question the partial and exclusionary nature of modern urban theory, in which 'modern' is synonymous of (North)Western Europe and North America. This can be challenged if we consider different 'alternative modernities', highlighting the geographical, historical, social and economic complexity of urban processes, this leading to an urban theory of differences.

\section{References}

Allen, J. (2000) A southern way of housing? London: Mimeo.

Arapoglou, V.P. and Sayas, J. (2009) New facets of urban segregation in southern Europe. European Urban and Regional Studies, 16(4), pp. 345-362.

Arbaci, S. (2008) (Re)Viewing Ethnic Residential Segregation in Southern European Cities: Housing and Urban Regimes as Mechanisms of Marginalisation, Housing Studies, 23(4), pp. 589-613.

Barata Salgueiro, T. (2001) Lisboa. Periferia e Centralidades. Oeiras: Celta

Bhatta, B., Saraswati, S. and Bandyopadhyay, D. (2010) Urban sprawl measurement from remote sensing data, Applied Geography, 30(4), pp. 731-740.

Bontje, M. and Burdack, J. (2005) Edge-cities European-style: Examples from Paris and the Randstad, Cities, 22(4), pp. 317-330.

Bourne, L. S. (2008) On School of Thought, Comparative Research, and Inclusiveness: a commentary, Urban Geography, 29(2), pp. 177-186.

Brueckner, J. K., Thisse, J. F. and Zenou, Y. (1999) Why is Central Paris Rich and Downtown Detroit Poor? An Amenity-based Theory, European Economic Review, 43(1), pp. 91-107. 
Bullard, D.R., Johnson, G. S. and Torres, A. O. (Eds) (2000) Sprawl City: Race, Politics and Planning in Atlanta. Washington: Island Press.

Busquets, J. (2006) Barcelona: the urban evolution of a compact city. Barcelona: Actar.

Calafati, A. (2008) Urban sprawl, Italian style, Italian Journal of Regional Sciences, 3(1), pp. 1018.

Catalán, B., Sauri, D. and Serra, P. (2008) Urban sprawl in the Mediterranean? Patterns of growth and change in the Barcelona Metropolitan Region 1993-2000, Landscape and Urban Planning, 85(3-4), pp. 174-184.

Cheshire, P. (1995) A New Phase of Urban Development in Western Europe? The Evidence for the 1980s, Urban Studies, 32(7), pp. 1045-1063.

Cheshire, P. C. and Hay, D.G. (1989) Urban problems in Western Europe, an economic analysis. London: Unwin Hyman.

Corna Pellegrini, G. (1998) An attemptable classification of the Mediterranean cities, in C. Vallat (Ed.), Petites et grandes villes du Bassin Méditerranéen - Études autour de l'œuvre d'Etienne Dalmasso,pp. 563-575.Roma: Collection de l'Ecole Française de Rome no. 246.

Costa, F., Noble, A. G. and Pendleton, G. (1991) Evolving planning systems in Madrid, Rome, and Athens, Geojournal, 24(3), pp. 293-303.

Couch, C., Karecha, J. and H. Nuissl (2005) Decline and sprawl: an evolving type of urban development-observed in Liverpool and Leipzig, European Planning Studies, 13(1), pp. 117136.

Couch, C., Leontidou, L. and Petschel-Held, G. (Eds) (2007) Urban Sprawl in Europe Landscapes, Land-Use Change \& Policy. Oxford: Blackwell Publishing.

Crisci, M. (2010) Italiani e stranieri nello spazio urbano. Dinamiche della popolazione di Roma. Milano: Franco Angeli.

Dalakoglou, D. (2012) Beyond spontaneity: Crisis, violence and collective action in Athens, City: analysis of urban trends, culture, theory, policy, action, 16(5), pp. 535-545.

Delladetsima, P. (2006) The emerging property development pattern in Greece and its impact on spatial development, European Urban and Regional Studies, 13(3), pp. 245-278.

Dematteis, G. (1998) Periurbanizzazione mediterranea e suburbanizzazione anglosassone. Vecchie e nuove forme della città estesa, in L. Viganoni (Ed.), Temi e problemi di geografia in memoria di Pietro Mario Mura, pp. 71-77. Roma: Gangemi.

Duany, A., Plater-Zyberk E. and Speck, J. (2000) Suburban Nation: The Rise of Sprawl and the Decline of the American Dream. New York: North Paint Press. 
Duran, B.S. and Odell, P.L. (1974) Cluster analysis. New-York: Springer-Verlag.

Ewing, R. (1994) Characteristics, Causes and Effects of Sprawl: A Literature Review, Environmental and Urban Issues, 21(2), pp. 1-15.

Ewing, R. (1997) Is Los Angeles-style sprawl desirable? Journal of the American Planning Association, 63(1), pp.107-126.

Fonseca, L., Caldeira, M. J. and Esteves, A. (2002) New Forms of Migration into the European South: Challenges for Citizenship and Governance. The Portuguese Case, International Journal of Population Geography, 8(2), pp. 135-152.

Fratini, F. (2001) Roma arcipelago di isole urbane. Uno scenario per il XXI secolo. Roma: Gangemi.

Galster, G., Hanson, R., Ratcliffe, M.R., Wolman, H., Coleman, S. and Freihage, J. (2001) Wrestling Sprawl to the Ground: Defining and Measuring an Elusive Concept, Housing Policy Debate, 12(4), pp. 681-717.

Gargiulo Morelli, V. and Salvati, L. (2010) Ad hoc urban sprawl in the Mediterranean city.Dispersing a compact tradition?Roma: Nuova Cultura.

Gemmiti, L., Salvati, L. and Ciccarelli, S. (2012) Mind the gap! 'Global' and 'Ordinary' cities in the planning perspective - Rome as a case study, International Journal of Latest Trends in Finance and Economic Science, 2(1), pp. 91-98.

Giaccaria, P. and Minca, C. (2011) The Mediterranean Alternative, Progress in Human Geography, 35(3), pp.345-365.

Hall, P. and Hay, D. (1980) Growth centres in the European Urban Systems. London: Heineman Educational Books.

Harvey, E. O. and Clark, W. (1965) The Nature and Economics of Urban Sprawl, Land Economics, 41(1), pp. 1-9.

Herzfeld, M. (1984) The horns of the Mediterraneanist dilemma, American Ethnologist, 11(3),pp. 439-454.

Herzfeld, M. (1985) Of horns and history. The Mediterraneanist dilemma again, American Ethnologist, 12(4), pp. 778-780.

Huang, J., Lu, X. X. and Sellers, J. M. (2007) A global comparative analysis of urban form: Applying spatial metrics and remote sensing, Landscape and Urban Planning, 82, pp. 184-197. Johnson, M.P. (2001) Environmental impacts of urban sprawl: a survey of the literature and proposed research agenda, Environment and Planning A, 33(4), pp. 717-735. 
Kantor, P. and Savitch, H. V. (2005) How to study comparative urban development politics: a research note, International Journal of Urban and Regional Research, 29(1), pp. 135-151.

Kloosterman, R. C. and Lambregts, B. (2007) Between accumulation and concentration of capital: Toward a framework for comparing long-term trajectories of urban systems, Urban Geography, 28(1), pp. 54-73.

Kourliouros, E. (2003) Reflections on the economic-noneconomic debate: a radical geographical perspective from the European south, Antipode, 35(4), pp. 781-799.

Lauf, S., Haase, D., Seppelt, R. and Schwarz, N.(2012) Simulating demography and housing demand in an urban region under scenarios of growth and shrinkage, Environment and Planning B: Planning and Design, 39(2), pp. 229 - 246.

Leontidou, L. (1990) The Mediterranean City in Transition - Social Change and Urban Development. New York: Cambridge University Press.

Leontidou, L. (1996) Alternatives to modernism in (Southern) urban theory: Exploring inbetween spaces, International Journal of Urban and Regional Research, 20(2), pp. 180-197.

Leontidou, L. (2010) Urban Social Movements in 'Weak' Civil Societies: The Right tothe City and Cosmopolitan Activism in Southern Europe, Urban Studies, 47(6), pp. 1179-1203.

Leontidou, L., Afouxenidis, A., Kourliouros, E. and Marmaras, E. (2007) Infrastructure-related urban sprawl: mega-events and hybrid peri-urban landscapes in southern Europe, in C. Couch,L. Leontidouand G. Petschel-Held (Eds.)Urban sprawl in Europe: landscapes, land-use change and policy, pp- 71-101. Oxford: Blackwell.

Longhi, C. and Musolesi, A. (2007) European cities in the process of economic integration: towards structural convergence, Annals of Regional Science, 41(2), pp. 333-351.

Malcata Rebelo, E. (2010) Does Urban Concentration/Dispersion Affect Immigrants' Professional Opportunities? The case of Porto Metropolitan Area, International Journal of Urban and Regional Research, 34(3), pp. 586-610.

Malheiros, J. and Vala, F. (2004) Immigration and city change: the region of Lisbon in the turn of the 20th century, Journal of Ethnic and Migration Studies, 30(6), pp. 1065-1086.

Maloutas, T. (2007) Segregation, social polarization and immigration in Athens during the 1990s: theoretical expectations and contextual difference, International Journal of Urban and Regional Research, 31(4), pp. 733-758.

Maloutas, T. and Karadimitriou, N. (2001) Vertical social differentiation in Athens: alternative or complement to community segregation, International Journal of Urban and Regional Research, 25(4), pp. 699-716. 
Martinuzzi, S., Gould, W.A. and Ramos Gonzalez, O.M.(2007) Land development, land use, and urban sprawl in Puerto Rico integrating remote sensing and population census data, Landscape and Urban Planning, 79, pp. 288-297.

McFarlane, C. (2010) The Comparative City: Knowledge, Learning, Urbanism,International Journal of Urban and Regional Research, 34(4), pp. 725-742.

Minca, C. (2004) Orizzonte mediterraneo. Padova: Cedam.

Mudu, P. (2006) Patterns of segregation in contemporary Rome,Urban Geography, 27(5), pp. $422-440$.

Munafò, M., Norero, C., Sabbi, A. and Salvati, L. (2010) Urban soil consumption in the growing city: a survey in Rome, Scottish Geographical Journal, 126(3), pp. 153-161.

Nijman, J. (2007) Introduction- Comparative Urbanism, Urban Geography, 28(1), pp. 1-6.

Patacchini, E. and Zenou, Y. (2009) Urban sprawl in Europe,Brookings-Wharton Papers on Urban Affairs 2009, pp. 125-149.

Phelps, N.A., Parsons, N., Ballas, D. and A. Dowling (2006) Post-suburban Europe: planning and politics at the margins of Europe's capital cities. Basingstoke: Palgrave Macmillan.

Reckien, D. and Karecha, J. (2007) Sprawl in European cities - the comparative background, in C. Couch, L. Leontidou and G. Petschel-Held (Eds.) Urban Sprawl in Europe: landscapes, landuse change \& policy, pp. 39-67. Oxford: Blackwell.

Richardson, H.W. and Chang-Hee, C. B. (Eds) (2004) Urban sprawl in Western Europe and the United States. London: Ashgate.

Robinson, J. (2006) Ordinary cities: between modernity and development. London: Routledge.

Robinson, J. (2011) Cities in a World of Cities: The Comparative Gesture, International Journal of Urban and Regional Research, 35(1), pp. 1-23.

Roy, A. (2005) Urban Informality. Toward an Epistemology of Planning, Journal of the American Planning Association, 71(2), pp. 147-158.

Salvati, L. and Zitti, M. (2009) The environmental 'risky' region: identifying land degradation processes through integration of socio-economic and ecological indicators in a multivariate regionalization model, Environmental Management, 44(5), pp. 888-899.

Schneider, A. and Woodcock, C. E. (2008) Compact, dispersed, fragmented, extensive? A comparison of urban growth in twenty-five global cities using remotely sensed data, pattern metrics and census information, Urban Studies, 45(3), pp. 659-692.

Schwartz, B. (1976) The Changing Face of the Suburbs. Chicago: University of Chicago Press 
Schwarz, N. (2010) Urban form revisited. Selecting indicators for characterising European cities, Landscape and Urban Planning, 96(1), pp. 29-47.

Vance, J. E. (1990) The Continuing City: Urban Morphology in Western Civilization. Baltimore: Johns Hopkins University Press.

Vicino, T.J., Hanlon, B. and Rennie Short, J. (2007) Megalopolis 50 Years on: the transformation of a city region, International Journal of Urban and Regional Research, 31(2), pp. 344-367.

Ward, K. (2010) Towards a relational comparative approach to the study of cities, Progress in Human Geography, 34(4), pp. 471-487.

Wilson, E. H., Hurd, J. D., Civco, D. L., Prisloe, S., and Arnold, C. (2003) Development of a geospatial model to quantify, describe and map urban growth, Remote Sensing of the Environment, 86(3), pp. 275-285. 
Table 1. Selected morphological characteristics of the six settlement's clusters for the three investigated regions.

\begin{tabular}{|c|c|c|c|c|c|c|}
\hline Variable & Old centre & $\begin{array}{l}\text { Hyper-compact } \\
\text { settlements }\end{array}$ & $\begin{array}{l}\text { Semi-compact } \\
\text { settlements }\end{array}$ & $\begin{array}{l}\text { Medium-density } \\
\text { settlements }\end{array}$ & $\begin{array}{l}\text { Low-density } \\
\text { settlements }\end{array}$ & $\begin{array}{l}\text { Dispersed } \\
\text { settlements }\end{array}$ \\
\hline \multicolumn{7}{|c|}{ Lisbon } \\
\hline Building density $\left(/ \mathrm{km}^{2}\right)$ & 29.0 & 10.0 & 9.1 & 7.2 & 5.9 & 3.5 \\
\hline Surface area $(\%)$ & 4.0 & 32.1 & 4.3 & 23.6 & 8.1 & 27.9 \\
\hline$\%$ buildings $<1945$ & 17.5 & 0.9 & 63.7 & 3.8 & 1.6 & 7.0 \\
\hline$\%$ buildings $1945-1970$ & 33.8 & 2.5 & 16.0 & 24.0 & 3.4 & 16.9 \\
\hline \% buildings 1970-1990 & 43.0 & 5.7 & 12.4 & 59.5 & 16.7 & 28.7 \\
\hline \% buildings 1990-2000 & 5.7 & 90.9 & 7.6 & 13.8 & 78.3 & 47.4 \\
\hline$\%$ buildings with 1-2 floors & 46.9 & 9.2 & 84.6 & 82.4 & 78.8 & 51.3 \\
\hline \multicolumn{7}{|c|}{ Rome } \\
\hline Building density $\left(/ \mathrm{km}^{2}\right)$ & 23.1 & 9.2 & 8.5 & 3.6 & 2.5 & 0.6 \\
\hline Surface area $(\%)$ & 6.3 & 25.1 & 29.0 & 3.0 & 23.2 & 13.4 \\
\hline$\%$ buildings $<1945$ & 93.9 & 19.1 & 11.5 & 83.1 & 8.2 & 7.6 \\
\hline \% buildings 1945-1970 & 4.9 & 65.8 & 40.5 & 8.8 & 30.5 & 27.9 \\
\hline \% buildings $1970-1990$ & 1.0 & 13.2 & 41.2 & 5.2 & 49.9 & 52.0 \\
\hline$\%$ buildings $1990-2000$ & 0.2 & 1.8 & 6.5 & 0.8 & 11.4 & 12.5 \\
\hline$\%$ buildings with $1-2$ floors & 24.4 & 11.5 & 50.8 & 75.2 & 84.6 & 95.0 \\
\hline \multicolumn{7}{|c|}{ Athens } \\
\hline Building density $\left(/ \mathrm{km}^{2}\right)$ & 35.3 & 31.9 & 25.6 & 12.8 & 7.6 & 3.9 \\
\hline Surface area $(\%)$ & 1.2 & 26.1 & 46.3 & 18.2 & 1.1 & 7.0 \\
\hline$\%$ buildings $<1945$ & 60.8 & 7.8 & 6.2 & 1.3 & 1.0 & 2.3 \\
\hline \% buildings 1945-1970 & 19.1 & 47.2 & 50.8 & 16.9 & 15.8 & 24.4 \\
\hline \% buildings 1970-1990 & 13.2 & 37.5 & 33.7 & 55.1 & 29.2 & 62.2 \\
\hline \% buildings 1990-2000 & 6.5 & 7.2 & 8.8 & 26.0 & 53.2 & 10.5 \\
\hline$\%$ buildings with $1-2$ floors & 94.3 & 36.7 & 81.7 & 85.2 & 96.0 & 98.8 \\
\hline
\end{tabular}


Table 2. Average value of the main indicators considered for Athens metropolitan area by settlement class.

\begin{tabular}{|c|c|c|c|c|c|c|c|}
\hline Variable & $\begin{array}{c}\text { Old } \\
\text { centre }\end{array}$ & $\begin{array}{c}\text { Hyper- } \\
\text { compact } \\
\text { settlements }\end{array}$ & $\begin{array}{c}\text { Semi- } \\
\text { compact } \\
\text { settlements }\end{array}$ & $\begin{array}{c}\text { Medium- } \\
\text { density } \\
\text { settlements }\end{array}$ & $\begin{array}{c}\text { Low- } \\
\text { density } \\
\text { settlements }\end{array}$ & $\begin{array}{c}\text { Dispersed } \\
\text { settlements }\end{array}$ & Average \\
\hline \% pop 0_14 & 11.3 & 14.6 & 20.7 & 15.6 & 11.5 & 13.3 & 14.0 \\
\hline \% рор 15-39 & 28 & 35.4 & 39.8 & 36.8 & 38.7 & 34.4 & 37.3 \\
\hline$\%$ pop $40-64$ & 33.9 & 31.6 & 30 & 34.7 & 32.2 & 34.1 & 32.6 \\
\hline$\%$ over 65 & 26.8 & 15.3 & 9.4 & 12.9 & 17.4 & 18.4 & 15.9 \\
\hline Mean age & 46.3 & 39.0 & 34.3 & 38.4 & 40.9 & 41.4 & 39.8 \\
\hline$\%$ uni.deg. & 7.9 & 10.2 & 7.7 & 15.7 & 17.0 & 6.2 & 12.3 \\
\hline \% hsc dipl. & 17.5 & 26.9 & 19.3 & 27.0 & 32.5 & 22.1 & 27.3 \\
\hline$\%$ readwrite & 10.7 & 4.6 & 5.1 & 3.3 & 2.7 & 6.6 & 4.3 \\
\hline$\%$ manag. & 7.3 & 9.4 & 7.8 & 13.8 & 9.0 & 10.3 & 10.2 \\
\hline$\%$ kn. work & 12.3 & 12.5 & 9.5 & 16.8 & 18.5 & 7.5 & 14.2 \\
\hline \%ntechempl. & 7.2 & 13.6 & 10.1 & 11.8 & 14.1 & 8.3 & 12.5 \\
\hline$\%$ ret sell & 9.7 & 15.1 & 13.9 & 11.9 & 14.8 & 12.8 & 13.9 \\
\hline$\%$ qual. work & 17.6 & 16.7 & 19.6 & 14.2 & 13.1 & 19.8 & 15.7 \\
\hline$\%$ unsp.work & 11.4 & 8.4 & 14.2 & 7.2 & 9.3 & 13.1 & 9.0 \\
\hline$\%$ employers & 11.7 & 11.4 & 10.4 & 15.8 & 9.4 & 14.9 & 12.2 \\
\hline \% s.e.work & 21.4 & 10.5 & 11.3 & 12.3 & 10.3 & 13.7 & 11.5 \\
\hline$\%$ waged & 57.5 & 76.6 & 76.8 & 69.7 & 79.3 & 67.7 & 74.3 \\
\hline$\%$ care & 4.8 & 1.5 & 1.4 & 1.9 & 0.9 & 3.7 & 1.8 \\
\hline Empl.rate & 36.4 & 39.7 & 38.3 & 41.5 & 41.3 & 36.6 & 40.2 \\
\hline Unempl.rate & 14.2 & 12.6 & 14.7 & 11.4 & 12.3 & 16.9 & 12.7 \\
\hline$\%$ Greek & 87.8 & 91.9 & 93.4 & 92.1 & 86.6 & 88.5 & 90.3 \\
\hline \% l.i.c & 11.7 & 7.9 & 7.2 & 6.1 & 13.1 & 10.2 & 9.1 \\
\hline \%h.i.c. & 7.3 & 1.4 & 0.8 & 3.1 & 2.7 & 1.4 & 2.1 \\
\hline
\end{tabular}


Table 3. Average value of the main indicators considered for Lisbon metropolitan area by settlement class.

\begin{tabular}{|c|c|c|c|c|c|c|c|}
\hline Variable & $\begin{array}{c}\text { Old } \\
\text { centre }\end{array}$ & $\begin{array}{c}\text { Hyper- } \\
\text { compact } \\
\text { settlements }\end{array}$ & $\begin{array}{c}\text { Semi- } \\
\text { compact } \\
\text { settlements }\end{array}$ & $\begin{array}{c}\text { Medium- } \\
\text { density } \\
\text { settlements }\end{array}$ & $\begin{array}{c}\text { Low- } \\
\text { density } \\
\text { settlements }\end{array}$ & $\begin{array}{l}\text { Dispersed } \\
\text { settlements }\end{array}$ & Average \\
\hline \% h.ownership & 61.7 & 85.5 & 51.4 & 78.0 & 89.7 & 70.8 & 70.8 \\
\hline$\%$ h.rental & 34.7 & 12.9 & 39.8 & 16.9 & 6.7 & 22.1 & 24.4 \\
\hline$\%$ hh $1-2 \mathrm{~m}$ & 53.6 & 40.4 & 59.3 & 44.5 & 36.2 & 48.6 & 48.4 \\
\hline$\%$ hh 3-4m & 40.1 & 53.0 & 33.2 & 46.8 & 54.2 & 42.7 & 43.9 \\
\hline$\%$ hh $5+m$ & 6.3 & 6.6 & 7.5 & 8.7 & 9.6 & 8.7 & 7.7 \\
\hline$\%$ pop $0-13$ & 11.2 & 21.1 & 10.1 & 12.5 & 16.8 & 11.8 & 12.6 \\
\hline \% pop 14-64 & 68.5 & 73.8 & 62 & 70.6 & 73.7 & 68.3 & 69.5 \\
\hline \% pop65+ & 20.2 & 5.2 & 27.8 & 16.8 & 9.5 & 19.8 & 17.9 \\
\hline Mean age & 44.4 & 34.9 & 48.1 & 42.5 & 38.1 & 44.0 & 43.0 \\
\hline Ageing index & 248.1 & 36.7 & 264.9 & 154.3 & 55.3 & 186.6 & 187.3 \\
\hline$\%$ read write & 11.4 & 14.2 & 17.1 & 12.4 & 12.3 & 14.9 & 12.8 \\
\hline$\%$ hsc dipl. & 15.0 & 19.3 & 10.0 & 13.2 & 15.9 & 11.2 & 13.9 \\
\hline$\%$ uni.deg. & 9.2 & 15.9 & 6.9 & 7.8 & 10.9 & 5.9 & 8.6 \\
\hline$\%$ prim sect & 0.5 & 0.3 & 1.9 & 1.1 & 0.9 & 2.2 & 1.1 \\
\hline$\%$ sec sect & 11.1 & 11.9 & 11.8 & 13.4 & 14.1 & 13.8 & 12.5 \\
\hline$\%$ ter sect & 34.2 & 44.3 & 28.3 & 31.8 & 35.9 & 28.9 & 33.0 \\
\hline$\%$ retired & 23.2 & 6.6 & 29.0 & 20.0 & 12.4 & 22.4 & 20.7 \\
\hline Empl.rate & 45.8 & 56.5 & 42.0 & 46.4 & 50.9 & 44.9 & 46.6 \\
\hline
\end{tabular}


Table 4. Average value of the main indicators considered for Rome metropolitan area by settlement class.

\begin{tabular}{|c|c|c|c|c|c|c|c|}
\hline Variable & $\begin{array}{c}\text { Old } \\
\text { centre }\end{array}$ & $\begin{array}{c}\text { Hyper- } \\
\text { compact } \\
\text { settlements }\end{array}$ & $\begin{array}{c}\text { Semi- } \\
\text { compact } \\
\text { settlements }\end{array}$ & $\begin{array}{c}\text { Medium- } \\
\text { density } \\
\text { settlements }\end{array}$ & $\begin{array}{c}\text { Low- } \\
\text { density } \\
\text { settlements }\end{array}$ & $\begin{array}{c}\text { Dispersed } \\
\text { settlements }\end{array}$ & Average \\
\hline Pop. Rep. index & 214.2 & 199.4 & 149.6 & 141.8 & 130.3 & 64.1 & 165.6 \\
\hline Act. p. Str. index & 115.8 & 104.5 & 99.8 & 109.6 & 98.6 & 147.2 & 103.1 \\
\hline Ageing index & 255.5 & 208.6 & 138.7 & 210.3 & 110.8 & 158.4 & 163.8 \\
\hline Mean age & 45.4 & 44.3 & 40.8 & 44.5 & 40.1 & 47.5 & 42.2 \\
\hline \% a. l. udeg. & 22.8 & 15.5 & 11.1 & 13.2 & 8.3 & 3.0 & 11.3 \\
\hline$\%$ a. l. hsc dipl. & 54.1 & 49.1 & 44.1 & 41.9 & 37.8 & 34.0 & 42.0 \\
\hline Empl. rate & 40.1 & 38.5 & 38.3 & 42.8 & 38.0 & 43.2 & 38.6 \\
\hline$\%$ manuf. & 9.5 & 10.0 & 12.4 & 7.7 & 13.2 & 13.9 & 10.5 \\
\hline$\%$ constr. & 5.7 & 5.2 & 7.4 & 5.3 & 9.1 & 9.9 & 6.7 \\
\hline \% comm. & 18.0 & 17.7 & 20.3 & 15.7 & 19.4 & 17.1 & 18.6 \\
\hline$\%$ r.e. & 11.4 & 10.9 & 9.0 & 6.2 & 6.9 & 5.1 & 8.8 \\
\hline$\%$ p. a. & 11.6 & 14.9 & 12.6 & 14.6 & 10.6 & 9.3 & 11.4 \\
\hline$\%$ edu. & 10.2 & 8.7 & 7.2 & 8.3 & 5.7 & 4.8 & 7.1 \\
\hline$\%$ entrepr. & 15.4 & 9.2 & 8.1 & 7.6 & 7.8 & 7.2 & 9.0 \\
\hline \% s.e.work & 13.7 & 10.7 & 13.9 & 11.3 & 17.0 & 18.2 & 13.8 \\
\hline$\%$ waged & 66.8 & 77.1 & 73.7 & 65.7 & 66.5 & 64.6 & 67.0 \\
\hline$\%$ retired & 18.2 & 18.9 & 15.0 & 12.8 & 13.9 & 14.0 & 14.9 \\
\hline$\%$ h.ownership & 58.1 & 65.9 & 71.6 & 71.4 & 71.8 & 72.9 & 69.9 \\
\hline$\%$ 1-2rooms & 19.2 & 11.0 & 10.0 & 18.4 & 10.0 & 9.1 & 10.1 \\
\hline$\% 5+$ rooms & 29.9 & 26.0 & 32.5 & 24.9 & 38.5 & 42.7 & 33.0 \\
\hline Home m.s. $\left(\mathrm{m}^{2}\right)$ & 88.6 & 79.8 & 92.1 & 90.6 & 108.0 & 88.9 & 92.3 \\
\hline Av. hhsize & 2.1 & 2.4 & 2.6 & 2.2 & 2.7 & 2.8 & 2.3 \\
\hline$\%$ n.I.Euro & 40.6 & 38.0 & 37.0 & 24.3 & 28.9 & 22.1 & 31.2 \\
\hline
\end{tabular}


Figure 1.Classification of the three investigated urban regions (Lisbon, Rome, Athens) into six settlements' categories (left: the whole examined region; right: a zoom on the strictly urban area).
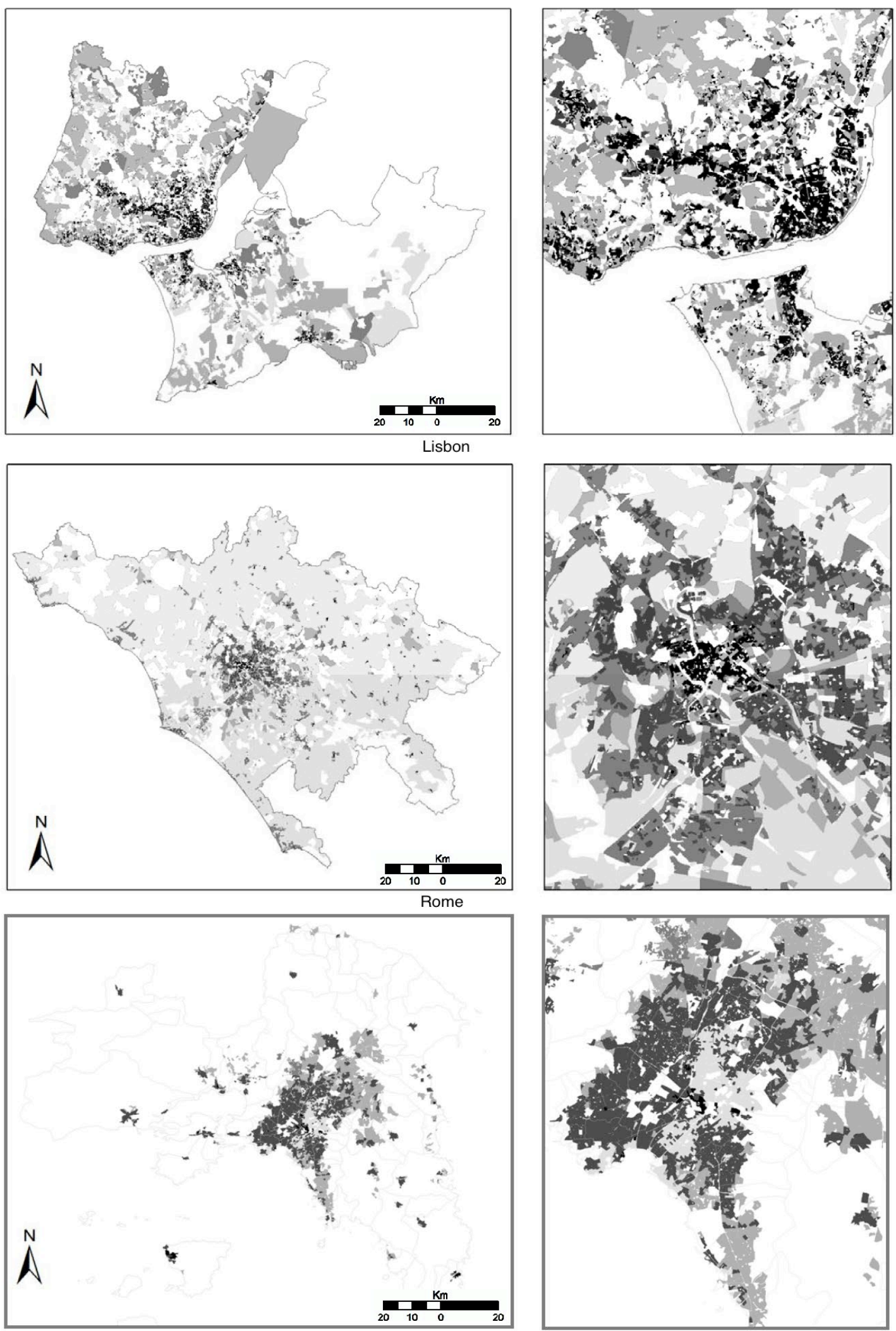

Old centre

Athens

Hyper-compact settlements 